\title{
Tratamento do Bagaço de Cana-de-açúcar com Uréia
}

\author{
Patrícia Sarmento ${ }^{1}$, Rasmo Garcia ${ }^{2}$, Aureliano José Vieira Pires ${ }^{3}$, Andréia Nascimento ${ }^{4}$
}

\begin{abstract}
RESUMO - O bagaço de cana contendo 55\% de matéria seca (MS) foi tratado com cinco níveis de uréia (0; 2,5; 5; 7,5; e 10\%) e 5\% de soja crua moída como fonte de urease, ambos com base na MS. O material foi armazenado por 97 dias em sacos plásticos (8 kg/saco de 50 L).e, após abertura, amostras foram coletadas em três períodos de aeração (2, 9 e 16 dias). Foi usado delineamento experimental inteiramente casualizado com três repetições. Não houve efeito de níveis de uréia para teor de MS; entretanto, a matéria seca elevou-se com o aumento dos períodos de aeração. Houve também aumento dos teores de proteína bruta e nitrogênio insolúvel em detergente ácido com o aumento dos níveis de uréia e redução com o aumento dos períodos de aeração. Não houve efeito para a fibra em detergente ácido, em função de níveis de uréia e períodos de aeração. A fibra em detergente neutro e a hemicelulose diminuíram com adição de uréia, mas elevaramse com o aumentos dos períodos de aeração. A digestibilidade in vitro da matéria seca aumentou com a adição de uréia. Os tratamentos com uréia alteraram a composição química, melhorando a qualidade do bagaço.
\end{abstract}

Palavras-chave: amonização, bagaço, cana-de-açúcar, digestibilidade, parede celular, proteína bruta, urease, uréia

\section{Treatment of Sugarcane Bagasse with Urea}

\begin{abstract}
Sugarcane bagasse with 55\% of dry matter (DM) was treated with five levels of urea (0, 2.5, 5, 7.5, and 10\%) and $5 \%$ ground whole soybean as a source of urease both, on a DM basis. The material was stored in plastic bags for $97 \mathrm{days}(8 \mathrm{~kg} /$ $50 \mathrm{~L}$ plastic bag), and after plastic bag opening, samples were collected at three aeration period (2, 9, and 16 days). A completely randomized design with three replicates was used. There was no effect of urea levels on dry matter content; however, dry matter increased with the increase of the aeration time. There were also increase of crude protein and acid detergent insoluble nitrogen (ADIN) with the increase of urea levels and reduction with the aeration periods increase. There was effect for ADF content as function of the urea levels and aeration periods. The neutral detergent fiber and hemicellulose contents decreased with the urea addition, but increased with the aeration periods. The in vitro dry matter disappearance increased with the addition of urea. The treatment with urea changed the chemical composition and improved the bagasse quality.
\end{abstract}

Key Words: ammoniation, bagasse, sugarcane, digestibility, cellular wall, crude protein, urease, urea

\section{Introdução}

O Brasil tornou-se o maior produtor mundial de álcool, com aproximadamente 12 bilhões de litros/ano e 8.500.000 t/ano de açúcar, devido à implantação do Programa Nacional do Álcool, que se iniciou na década de 1970 (BURGI, 1995).

Em decorrência dessa crescente atividade sucroalcooleira, vários pesquisadores têm conduzido diversos estudos de utilização dos subprodutos da cana, como levedura, vinhaça, torta de filtro, ponta de cana e bagaço, sendo que este último, quantitativamente, é o mais importante.

A produção de bagaço de cana-de-açúcar foi estimada em 75 milhões de toneladas a cada ano (BÜRGI, 1995), e vêm ocorrendo crescentes alterna- tivas de seu uso. Além da utilização como integrante da ração de ruminantes, o bagaço tem sido utilizado como adubo orgânico composto, cobertura morta para certas culturas, indústrias de papel, material absorvente, entre outros.

O bagaço in natura é um produto fibroso resultante do esmagamento da cana-de-açúcar para obtenção de açúcar, álcool ou aguardente (SANTANA e SOUZA, 1985). Por ser considerado alimento de baixa qualidade para ruminantes, rico em fibra, baixo conteúdo celular, baixa digestibilidade, pobre em proteínas e minerais (SANTOS, 1990), o seu uso será eficiente somente se o valor nutritivo for melhorado por meio de tratamento químico e/ou físico.

Segundo MATTOS (1985), o composto químico deve possuir certas características para que sua

\footnotetext{
${ }^{1}$ Estudante de Mestrado da ESALQ, Piracicaba, SP

${ }^{2}$ Professor da UFV, Viçosa, MG

${ }^{3}$ Professor da UESB, Itapetinga, BA.

${ }^{4}$ Zootecnista, UFV, Viçosa, MG.
} 
utilização possa ser recomendada em larga escala: deve promover aumento efetivo na digestibilidade e/ou consumo do material; o custo do tratamento deve ser viável; o produto químico deve ter alta disponibilidade no mercado; o resíduo químico, no material tratado, não pode ser tóxico ao animal e as fezes e a urina não devem ser fontes de poluição de solos e cursos da água; o composto químico deve ser nutriente exigido pelo animal ou possuir valor fertilizante; o agente químico deve ter ação preservativa, no caso de conservação do material tratado; não deve ser tóxico e nem corrosivo ao homem; e é desejável que a reação química seja rápida.

Os produtos químicos que podem ser utilizados em escala industrial ou em nível de produtor, provavelmente, resumem-se a hidróxido de sódio, amônia e uréia. No entanto, o uso do $\mathrm{NaOH}$ vem diminuindo, por influir negativamente no balanço mineral, aumentar a taxa de passagem da parede celular no rúmen e diminuir as atividades das bactérias celulolíticas, proporcionando decréscimo na digestão das fibras potencialmente digestíveis no rúmen. Segundo TEIXEIRA (1990), o uso do $\mathrm{NaOH}$ provoca, também, aumento da ingestão de água e, conseqüentemente, aumento de excreção urinária, eliminando assim o excesso de sódio ingerido, o qual pode resultar em acúmulo de sódio no solo.

A amonização preenche a maior parte dos requisitos citados, promovendo aumento nos teores de nitrogênio não-protéico e atuando na fração fibrosa do alimento, causando solubilização de parte da hemicelulose, aumentando, assim, a digestibilidade e o consumo de volumosos de baixa qualidade (GARCIA, 1992), além de atuar como fungiostático na conservação do material amonizado (CAMPOS, 1995; PIRES, 1995).

Em certas regiões, a amônia líquida e a anidra não são disponíveis, sendo de difícil aquisição. A uréia é alternativa, por ser considerada produto de alta disponibilidade, menos perigosa à intoxicação humana e, muitas vezes, menos onerosa, tornando-se, portanto, produto viável como fonte de amônia.

A uréia, um sólido cristalino produzido tecnicamente a partir da amônia e do dióxido de carbono, contém $45 \%$ de nitrogênio e $28 \%$ de equivalente protéico e apresenta a propriedade de se dissolver facilmente em água formando a amônia.

Na presença da enzima urease, a uréia é desdobrada para produção de amônia, que, em certas condições, se torna necessária à adição de alguma fonte de urease, para garantir melhor eficiência do tratamento.
Vários autores têm encontrado modificações na composição química bromatológica do material tratado com o tempo de exposição ao ambiente (FERREIRA, 1989; REIS, 1989; e PIRES, 1995), como a diminuição do teor de proteína bruta, por causa da volatização do N (PIRES, 1995). No entanto, como estas modificações diferem conforme a natureza do material, faz-se necessária a avaliação do comportamento da composição bromatológica do bagaço tratado, em função dos períodos de aeração.

O objetivo deste trabalho foi avaliar o efeito da amonização do bagaço de cana-de-açúcar, com níveis crescentes de uréia, sobre a composição químico-bromatológica nos períodos de aeração.

\section{Material e Métodos}

Este trabalho foi realizado no Departamento de Zootecnia da Universidade Federal de Viçosa. A cana-de-açúcar foi beneficiada na Usina de Rio Branco (MG) e o subproduto (bagaço) foi transportado para Viçosa e armazenado em local coberto. Após recebimento, o bagaço foi misturado com os diferentes níveis de uréia $(0 ; 2,5 ; 5 ; 7,5 ;$ e $10 \%$ base na MS ) e $5 \%$ de soja crua moída (base na MS em relação ao bagaço) e posteriormente ensacado (8 kg/saco de 50 litros), sendo os sacos fechados hermeticamente com fita adesiva. Os sacos plásticos foram cobertos por lona plástica e deixados a céu aberto por período de 97 dias.

Após abertura dos sacos, foram retiradas amostras após três períodos de aeração (2, 9 e 16 dias). $\mathrm{O}$ material foi homogeneizado primeiramente, seguido de coleta e armazenamento das amostras em câmara fria. Posteriormente, realizou-se a secagem e moagem do material para subsequentes análises bromatológicas. As amostras foram secas à temperatura de $40^{\circ} \mathrm{C}$ para minimizar perdas de amônia por volatilização.

As análises de matéria seca (MS), proteína bruta (PB), fibra em detergente neutro (FDN), fibra em detergente ácido (FDA), hemicelulose (HEM) e nitrogênio insolúvel em detergente ácido (NIDA) foram feitas de acordo com os procedimentos descritos por SILVA (1990). Foi também analisada a digestibilidade in vitro da matéria seca (DIVMS), utilizando-se a técnica de TILLEY e TERRY (1963).

O delineamento experimental adotado foi o inteiramente casualizado em esquema de parcelas subdivididas com três repetições, tendo na parcela cinco níveis de uréia e na subparcela, três períodos de aeração. Foi utilizado o programa estatístico SANEST (USP) para análise dos dados. 


\section{Resultados e Discussão}

A amonização do bagaço de cana, por meio de diferentes níveis de uréia, não alterou significativamente o teor de MS; no entanto, houve diminuição significativa da umidade $(\mathrm{P}<0,01)$ nos períodos de aeração, porque o bagaço estava exposto ao ar e, conseqüentemente, à desidratação constante, como se verifica na Tabela 1 . Resultado semelhante de aumento do teor de MS, nos períodos de aeração, foi constatado por PIRES (1995), quando utilizou níveis de amônia anidra $0,1,2$ e $3 \%$, com períodos de aeração de $0,7,14,21$ e 28 dias, em quirera de milho com alto teor de umidade.

No entanto, tem-se encontrado aumento no teor de umidade, à medida que se aumenta o tempo de exposição do material tratado com amônia anidra. PAIVA (1992) explica esse fato pela alta afinidade da amônia com a umidade do ar, quando o material tratado apresenta baixa umidade (10\%).

No trabalho realizado por PIRES (1995), não houve diminuição no teor de MS, provavelmente porque a quirera apresentou alto teor de umidade (25\%), assim como o bagaço de cana tratado com uréia (57\% de umidade). Como o presente trabalho refere-se também à amonização, pela uréia, no entanto, considerou-se a explicação de PAIVA e PIRES satisfatória também para esta situação.

A equação obtida pela análise de regressão polinomial para o parâmetro teor de MS, em função

Tabela 1 - Teores médios de matéria seca (MS) no bagaço de cana tratado com cinco níveis de uréia e três períodos de aeração

Table 1 - Average dry matter (DM) contents of the sugarcane bagasse treated with five levels of urea and three aeration periods

Nível de uréia (\%) Períodos de aeração (dias)

Urea level

\begin{tabular}{lrl} 
Aeration period (days) \\
\hline 2 & 9
\end{tabular}

Média Mean

\begin{tabular}{lcccc}
\hline \multicolumn{5}{c}{ Materia seca (\%) } \\
\multicolumn{5}{c}{ Dry matter } \\
0,0 & 59,01 & 67,75 & 73,18 & 66,65 \\
2,5 & 57,58 & 64,55 & 70,34 & 64,15 \\
5,0 & 58,91 & 63,30 & 68,98 & 63,73 \\
7,5 & 52,57 & 52,66 & 58,04 & 54,42 \\
10,0 & 58,02 & 58,42 & 63,81 & 60,08 \\
Média & 57,22 & 61,34 & 66,87 &
\end{tabular}

Mean

CV para os níveis de uréia $=8,95 \%$, e para os períodos de aeração $=1,82 \%$.

CV for urea levels $=8.95 \%$, and for aeration periods $=1.82 \%$.

F para níveis de uréia $=2,20$, e para os períodos de aeração $=278,37$.

$F$ for urea levels $=2.20$, and for aeration periods $=278.37$. dos períodos de aeração, foi:

$$
\hat{\mathrm{Y}}=56,9823+0,6894 \mathrm{X} \quad \mathrm{R}^{2}=0,9929
$$

$\mathrm{O}$ teor de $\mathrm{PB}$ aumentou $(\mathrm{P}<0,01)$ com os níveis de uréia e diminuiu $(\mathrm{P}<0,01)$ com os períodos de aeração (Tabela 2). Estes aumentos de PB para níveis de uréia foram encontrados também nos trabalhos realizados por WAISS et al. (1972), SUNDSTOL et al. (1978), DOLBERG (1981) e FAHMY e KLOPEENSTEIN (1994). Esses aumentos são explicados pela adição do nitrogênio não-protéico aplicado em níveis crescentes no material com a amonização; portanto, na determinação de nitrogênio total, esses valores são computados ao teor de PB.

A queda do teor de PB do material amonizado com o aumento do período de aeração ocorreu por causa da volatilização do nitrogênio. Este fato foi constatado também por PIRES (1995).

Na análise de regressão polinomial para o parâmetro $\mathrm{PB}$, foram obtidas as equações para os níveis de uréia e períodos de aeração, respectivamente:

$$
\begin{aligned}
& \hat{Y}=3,4324+0,9174 X ; R^{2}=0,9972 \\
& \hat{Y}=8,8620-0,2218 X+0,0087 X^{2} R^{2}=1,0000
\end{aligned}
$$

Quanto aos teores de FDA, não foi observado efeito significativo $(\mathrm{P}>0,01)$ para os níveis de uréia aplicados e períodos de aeração (Tabela 3 ), o que se deve ao fato de a amônia não causar alterações nas frações da celulose e lignina, as quais são constituintes do FDA. Resultados semelhantes foram encontrados por BONJARDIM (1989), BONJARDIM et

Tabela 2 - Teores médios de proteína bruta (PB) no bagaço de cana tratado com cinco níveis de uréia e três períodos de aeração

Table 2 - Average crude protein (CP) contents of sugarcane bagasse as treated with five levels of urea and three aeration periods

Períodos de aeração (dias)

Aeration period (days)

\begin{tabular}{lcccc} 
Nível de uréia (\%) & 2 & 9 & 16 & $\begin{array}{c}\text { Média } \\
\text { Urea level }\end{array}$ \\
\cline { 2 - 3 } & \multicolumn{3}{c}{$\begin{array}{c}\text { Proteína bruta (\%) } \\
\text { Crude protein }\end{array}$} \\
0,0 & 3,95 & 3,51 & 3,49 & 3,65 \\
2,5 & 5,92 & 5,12 & 5,74 & 5,59 \\
5,0 & 9,01 & 7,37 & 6,74 & 7,71 \\
7,5 & 11,03 & 9,95 & 8,90 & 9,96 \\
10,0 & 14,16 & 11,72 & 11,74 & 12,54 \\
Média & 8,81 & 7,53 & 7,32 &
\end{tabular}

Mean

CV para os níveis de uréia $=9,53 \%$, e para os períodos de aeração $=6,56 \%$

CV for urea levels $=9.53 \%$, and for aeration periods $=6.56 \%$.

F para níveis de uréia $=67,67$, e para os períodos de aeração $=29,89$.

$F$ for urea levels $=67.67$, and for aeration periods $=29.89$. 
al. (1992) e PAIVA (1992), trabalhando com amônia anidra. Entretanto, há autores que verificaram aumento nos teores de FDA em forragens armazenadas, em decorrência da incorporação do $\mathrm{N}$ proveniente da amônia à fração fibrosa, por meio da reação de amonólise (THORLACIUS e ROBERTSON, 1984). HANSSOUN et al. (1990), quando amonizaram bagaço de cana-de-açúcar com uréia, verificaram aumento nos teores de FDA $(\mathrm{P}<0,01)$ para os níveis crescentes de uréia $(70,88,106$ e $124 \mathrm{~g} / \mathrm{kg}$ base na MS).

A amonização do bagaço diminuiu $(\mathrm{P}<0,01)$ os teores de FDN e hemicelulose, para os níveis crescentes de uréia, e aumentou para os períodos de aeração (Tabelas 4 e 5). A determinação da hemicelulose deu-se por meio da subtração entre FDN e FDA.

A diminuição do FDN em forragens é atribuída à solubilização da hemicelulose (VAN SOEST et al., 1984). No presente trabalho, como nos demais, ocorreu redução de FDN e/ou hemicelulose, e essas foram mais elevadas, quando houve incrementos dos níveis de $\mathrm{NH}_{3}$.

Este fato pode ser verificado em razão da não alteração de outros componentes da parede celular, como celulose e lignina, que são obtidas a partir da determinação do FDA.

Semelhantes resultados da diminuição da hemicelulose e FDN de materiais amonizados foram encontrados por REIS (1989), HASSOUN et al. (1990), REIS et al. (1990), FERREIRA et al. (1990),

Tabela 3 - Teores médios de fibra em detergente ácido (FDA) no bagaço de cana tratado com cinco níveis de uréia, são três períodos de aeração

Table 3 - Average acid detergent fiber (ADF) contents of sugarcane bagasse treated with five levels of urea, under three aeration periods

Nível de uréia (\%) Períodos de aeração (dias)

Urea level Aeration period (days)

\begin{tabular}{lcccc}
\cline { 2 - 3 } & 2 & 9 & 16 & $\begin{array}{c}\text { Média } \\
\text { Mean }\end{array}$ \\
\hline \multicolumn{5}{c}{ FDA (\%) } \\
& ADF \\
0,0 & 60,21 & 60,77 & 59,04 & 60,01 \\
2,5 & 62,15 & 62,65 & 60,89 & 61,90 \\
5,0 & 61,62 & 61,87 & 63,42 & 62,30 \\
7,5 & 61,65 & 63,24 & 63,55 & 62,81 \\
10,0 & 60,50 & 62,01 & 62,80 & 61,77 \\
Média & 61,23 & 62,11 & 61,94 &
\end{tabular}

Mean

CV para os níveis de uréia $=1,44 \%$, e para os períodos de aeração $=1,71 \%$.

CV for urea levels $=1.44 \%$, and for periods aeration $=1.71 \%$.

$F$ para níveis de uréia $=4,28$, e para os períodos de aeração $=2,95$.

$F$ for urea levels $=4.28$, e for periods aeration $=2.95$.
TEIXEIRA (1990), PAIVA (1992) e PIRES (1995).

Aumentos nos teores de FDN e hemicelulose durante o período de aeração também foram alcançados por REIS (1989) em fenos de capim-braquiária, quando avaliou alterações químico-bromatológicas que poderiam ocorrer durante o período de aeração de 60 dias.

As equações obtidas pela análise de regressão polinomial dos parâmetros FDN e hemicelulose (HEM) para os níveis de uréia e período de aeração são, respectivamente:

$$
\begin{aligned}
\text { FDN }: & \hat{Y}=90,5338-0,5139 X ; R^{2}=0,8664 \\
\hat{Y} & =86,7097+0,1792 X ; R^{2}=0,9845 \\
\text { HEM: } & \hat{Y}=29,7993-0,7141 X ; R^{2}=0,9637 \\
\hat{Y} & =25,4637+0,1093 X ; R^{2}=0,7667
\end{aligned}
$$

Foram observados aumentos significativos $(\mathrm{P}<0,01)$ nos teores de NIDA, de acordo com os níveis de uréia, mas não foi verificado efeito quanto aos períodos de aeração $(\mathrm{P}>0,01)$ (Tabela 6). Os resultados de aumento nos teores de NIDA também foram encontrados por REIS (1989), PAIVA (1992) e CAMPOS (1995). Valores de nitrogênio insolúvel em detergente ácido (NIDA) têm sido utilizados por alguns pesquisadores como indicadores da quantidade de compostos nitrogenados amoniacais ligados covalentemente aos componentes da fração fibrosa das forragens tratadas pela amonização (FISCHER et al., 1985).

A amonização pode promover aumento nos teores de NIDA das forragens, cujos conteúdos podem

Tabela 4 - Teores médios de fibra em detergente neutro (FDN) no bagaço de cana tratado com cinco níveis de uréia, são três períodos de aeração

Table 4 - Average neutral detergent fiber (NDF) contents of sugarcane bagasse as treated with five levels of urea, under three aeration periods

Nível de uréia (\%) Períodos de aeração (dias)

Urea level

Aeration period (days)

\begin{tabular}{lcccc}
\cline { 2 - 3 } & 2 & 9 & 16 & $\begin{array}{c}\text { Média } \\
\text { Mean }\end{array}$ \\
\hline \multicolumn{5}{c}{$\begin{array}{c}\text { FDN (\%) } \\
\text { NDF }\end{array}$} \\
0,0 & 89,51 & 88,94 & 90,83 & 89,76 \\
2,5 & 89,20 & 89,70 & 90,78 & 89,89 \\
5,0 & 87,65 & 88,67 & 89,98 & 88,77 \\
7,5 & 84,10 & 86,47 & 88,14 & 86,24 \\
10,0 & 83,62 & 85,13 & 86,81 & 85,19 \\
Média & 86,82 & 87,78 & 89,31 & \\
Mean & & & &
\end{tabular}

$\overline{\mathrm{CV}}$ para os níveis de uréia $=1,48 \%$, e para os períodos de aeração $=1,71 \%$.

CV for urea levels $=1.48 \%$, and for aeration periods $=1.71$.

F para níveis de uréia $=8,18$, e para os períodos de aeração $=10,59$.

$F$ for urea levels $=8.18$, and for aeration periods $=10.59$. 
Rev. bras. zootec.

Tabela 5 - Teores médios de hemicelulose (HEM) no bagaço de cana tratado com cinco níveis de uréia e três períodos de aeração

Table 5 - Average hemicellulose (HEM) contents of sugarcane bagasse treated with five levels of urea, under there

Nível de uréia (\%) Períodos de aeração (dias)

Urea level

\begin{tabular}{ccc} 
Aeration period (days) & Média \\
\hline 2 & 9 & 16
\end{tabular}

\begin{tabular}{lcccc}
\hline \multicolumn{4}{c}{ Hemicelulose (\%) } \\
Hemicellulose \\
0,0 & 29,30 & 28,17 & 31,79 & 29,75 \\
2,5 & 27,05 & 27,05 & 29,89 & 28,00 \\
5,0 & 26,02 & 26,79 & 26,56 & 26,46 \\
7,5 & 22,45 & 23,56 & 24,58 & 23,53 \\
10,0 & 23,05 & 23,13 & 24,02 & 23,40 \\
Média & 25,57 & 25,74 & 27,37 &
\end{tabular}

Mean

CV para os níveis de uréia $=2,36 \%$, e para os períodos de aeração $=4,82 \%$.

CV for urea levels $=2.36 \%$, and for aeration periods $=4.82 \%$.

F para níveis de uréia $=65,00$, e para os períodos de aeração $=7,15$.

$F$ for urea levels $=65.00$, and for aeration periods $=7.15$.

atingir valores superiores a $20 \%$ do nitrogênio total (REIS et al., 1991); no entanto, esses materiais têm sua utilização comprometida, em razão de reduções na disponibilidade de nitrogênio e indicam problemas de superaquecimento (Yu e Thomas, 1976, citados por PIRES, 1995).

A equação obtida pela análise de regressão polinomial do parâmetro NIDA para os níveis de uréia é:

$$
\hat{\mathrm{Y}}=0,2142+0,0213 \mathrm{X} ; \mathrm{R}^{2}=0,9837
$$

Quanto aos teores de digestibilidade in vitro da matéria seca (DIVMS), a amonização aumentou significativamente $(\mathrm{P}<0,01)$ para níveis crescentes de uréia (Tabela 7). As alterações na digestibilidade do bagaço com a amonização ocorreram devido a diminuições nos teores de FDN e hemicelulose e incremento nos níveis de PB pelo tratamento químico.

A maioria dos trabalhos com amonização de forragens tem mostrado aumento da DIVMS, como foi constatado por BONJARDIM et al. (1992) e CAMPOS (1995), utilizando amônia anidra. VILELA et al. (1987) e HASSOUN et al. (1990), utilizando uréia na amonização do silagem de capim elefante e bagaço de cana, respectivamente, também verificaram incremento da DIVMS.

A equação obtida pela análise de regressão polinomial do parâmetro digestibilidade da matéria seca (DIVMS) para os níveis de uréia é:

$\hat{\mathrm{Y}}=32,2944+3,8228 \mathrm{X}+0,2078 \mathrm{X}^{2} ; \mathrm{R}^{2}=0,9445$

Em relação à contaminação por fungos do materi-
Tabela 6 - Teores médios de nitrogênio insolúvel em detergente ácido (NIDA) no bagaço de cana tratado com cinco níveis de uréia e três períodos de aeração

Table 6 - Average acid detergent insoluble nitrogen (ADIN) contents of sugarcane bagasse treated with five levels of urea, under three aeration periods

Nível de uréia (\%) Períodos de aeração (dias)

Urea level

Aeration period (days)

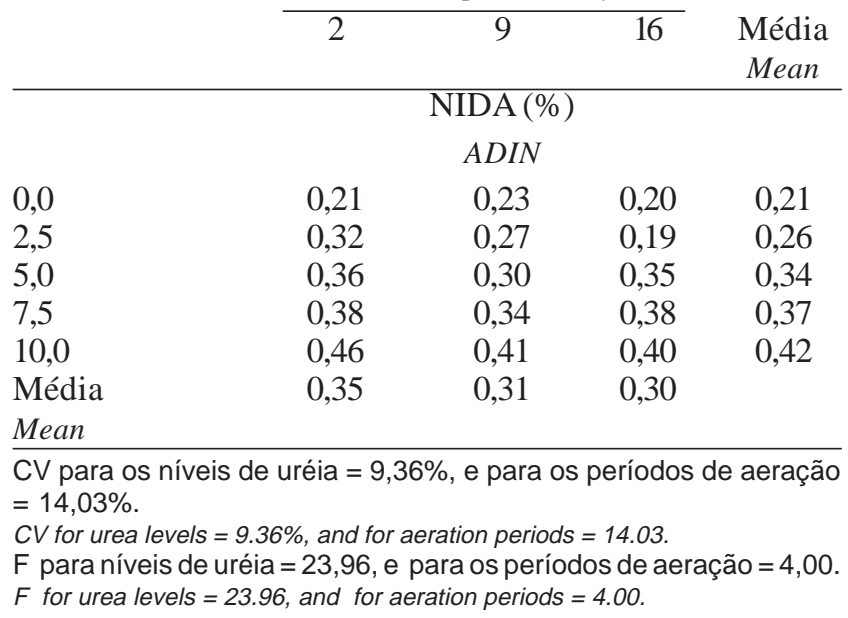

Tabela 7 - Teores médios da digestibilidade in vitro da matéria seca (DIVMS) do bagaço de cana tratado com cinco níveis de uréia

Table 7 - $\quad$ Average in vitro dry matter disappearence (IVDMD) of the sugarcane bagasse treated by five levels of urea Níveis de uréia (\%) Levels of urea

\begin{tabular}{cccccc}
\cline { 2 - 5 } & 0,0 & 2,5 & 5,0 & 7,5 & 10,0 \\
\hline DIVMS (\%) & 32,89 & 45,49 & 48,58 & 48,44 & 50,65
\end{tabular}

IVDMD

CV para níveis de uréia $=4,22 \%$.

CV for urea levels $=4.22 \%$.

$\mathrm{F}$ para os níveis de uréia $=50,19$.

$F$ for urea levels $=50.19$

al, observou-se que, nos tratamentos que não receberam uréia, ocorreu a proliferação de fungos. O tratamento com $2,5 \%$ de uréia não foi suficiente para evitar o desenvolvimento de fungos, o que pode ser observado no material a partir de 9 dias de aeração. Os demais tratamentos $(5 ; 7,5$; e $10 \%$ de uréia) mostraram-se eficientes na conservação do material até 16 dias de aeração.

CAMPOS (1995) e PIRES (1995) constataram que o nível de $1 \%$ de amônia anidra não foi eficiente na conservação do material tratado, sendo constatada a presença de fungos nesse nível, assim como para o controle. No trabalho de PIRES (1995), os níveis de 2 e 3\% de amônia anidra proporcionaram perfeita conservação da quirera de milho com alta umidade, em período de até 28 dias. 


\section{Conclusões}

A amonização do bagaço de cana-de-açúcar utilizando uréia resultou no aumento da DIVMS, PB e NIDA e diminuição da FDN e hemicelulose; entretanto, a MS e FDA não sofreram alterações.

Em relação aos períodos de aeração, observouse diminuição da PB e aumento de FDN e hemicelulose, enquanto os teores de MS, FDA e NIDA não foram alterados.

\section{Referências Bibliográficas}

BONJARDIM, S.R., REIS, R.A., RODRIGUES, L.R.A. et al. 1992. Avaliação da qualidade dos fenos de gramíneas tropicais armazenados com diferentes níveis de umidade e tratados com amônia. R. Soc. Bras. Zootec., 21(5):866-873.

BUETTNER, M.R., LECHTENBERG, V.L., HENDRIX, K.S. et al. 1982. Composition and digestion of ammoniated tall fescue (Festuca arundinacea Schreb.) hay. J. Anim. Sci., 54(1):173-8.

BÜRGI, R. Cana-de-açúcar. In: SIMPÓSIO DE NUTRIÇÃO DE PlantAS, 6, 1995, Piracicaba. Anais... Piracicaba: FEALQ, 1995, p. 153-170.

CAMPOS, M.C.L. Níveis de amônia anidra e períodos de amonização sobre a composição químico-bromatológiaca e degradabilidade dos fenos de alfafa (Medicago sativa L.) $e$ coast-cross (Cynodon dactylon (L.) Pers. cv. coastcross) com alta umidade. Viçosa, MG: UFV, 1995. 135p. Dissertação (Mestrado em Zootecnia) - Universidade Federal de Viçosa, 1995.

DOLBERG, F., SAADULlAH, M., HAQUE, M. et al. 1981. Almacenamiento de la paja tratada co urea. R. Mund. Zootec., 38:37- 41.

FAHMY, S.T.M., KLOPFENSTEIN, T.J. 1994. Treatment with different chemicals and their effects on in vivo digestibility as affected by chemical treatment and monsensin supplementation. Anim. Feed Sci. Technol., 45:309-316.

FERREIRA, J.Q., GARCIA, R., QUEIROZ, A.C. et al. 1990. Efeito da amônia anidra sobre a qualidade da palha de arroz (Oryza sativa L.) e do feno de aveia (Avena strigosa Schreb.). R. Soc. Bras. Zootec., 19(1):39-43.

FERREIRA, J.Q. Efeito da amônia anidra sobre a qualidade da palha de arroz (Oryza sativa L.) e feno de aveia (Avena strigosa Schreb.). Viçosa, MG: UFV, 1989. 110p. Dissertação (Mestrado em Zootecnia) - Universidade Federal de Viçosa, 1989.

FISCHER, R.E., BAYLEY, P., HARRISON, K.E. et al. 1985. Nutritive value of coastal bermudagrass hay as influenced by ammoniation and grain supplementation. Arkansas Farm Res., 34(3):8.

GARCIA, R. Amonização de forragens de baixa qualidade e a utilização na alimentação de ruminantes. In: SIMPÓSIO SOBRE UTILIZAÇÃO DE SUBPRODUTOS AGROINDUSTRIAIS E RESÍDUOS DE COLHEITA NA ALIMENTAÇÃO DE RUMINANTES, 1992, Piracicaba. Anais... Piracicaba: FEALQ, 1992, p.83-97.

HASSOUN, P., GEOFFROY, F., SAMINADINI, G. et al. 1990. Studies on the ammoniation of sugar-cane bagasse by urea. Effects of moisture, urea levels, urease source and treatment periods on composition, in vitro dry matter digestibility and evolution of ureolytic bacteria. Anim. Feed Sci. Technol., 29:113-129.
MATTOS, W.R.S. Utilização do bagaço de cana-de-acúcar na alimentação de ruminantes. In: SIMPÓSIO SOBRE UTILIZAÇÃO DE RESÍDUOS AGROINDUSTRIAIS DA CANADE-AÇÚCAR NA ALIMENTAÇÃO DE RUMINANTES, 1985, Piracicaba. Anais... Piracicaba: FEALQ, 1985, p.53.

MOORE, K.J., LECHTENBERG, V.L., HENDRIX, K.S. 1985. Quality of orchargrass hay ammoniated at different rates, moisture concentrations, and treatment durations. Agron. J., 77:67-71.

PAIVA, J.A.J. Níveis de amônia anidra, períodos de amonização e de aeração sobre a composição químico bromatológica e a degradabilidade in situ da palha de milho (Zea mays L.). Viçosa, MG, UFV, 1992. 162p. Tese (Doutorado em Zootecnia) - Universidade Federal de Viçosa, 1991.

PIRES, A.J.V. Efeito da amônia anidra sobre a conservação e composição químico-bromatológica da quirela de milho (Zea mays L.) com alta umidade. Viçosa, MG: UFV, 1995, 70p. Dissertação (Mestrado em Zootecnia) - Universidade Federal de Viçosa, 1995.

REIS, R.A. Efeitos da aplicação de amônia anidra sobre o valor nutritivo dos fenos de graníneas forrageiras de clima tropical. Viçosa, MG: UFV, 1989. 119p. Tese (Doutorado em Zootecnia) - Universidade Federal de Viçosa, 1989.

REIS, R.A., GARCIA, R., SILAVA, D.J. et al. 1990. Efeitos da Aplicação de amônia anidra sobre a digestibilidade do feno do capim-braquiária (Brachiaria decumbens Stapf). R. Soc. Bras. Zootec., 19(3):201-208.

SANTANA, J., SOUZA, S.O. 1984. Subprodutos da cana-deaçúcar. Inf. Agropec., 10(119):22- 27.

SANTOS, F.A.P. O bagaço de cana-de-açúcar tratado sob pressão de vapor como alternativa para a alimentação de bovinos na entressafra das pastagens. In: REUNIÃO ANUAL DA SOCIEDADE BRASILEIRA DE ZOOTECNIA, 25, 1990, Campinas. Anais... Campinas, 1990, 203p.

SILVA, D.J. 1990. Análise de alimentos (métodos químicos e biológicos). 2 ed. Viçosa, MG, UFV. Impr. Univ. 165p.

SUNDSTOL, F., COXWORTH, E., MOWAT, D.N., 1978. Improving the nutritive value of straw and other low-quality roughages. World Anim. R., 26:13-21.

TEIXEIRA, J.R.C. Efeito da amônia anidra no valor nutritivo da palha de milho mais sabugo e do capim elefante (Pennisetum purpureum Schum) cv. Camerom fornecidos a novilhos nelore em confinamento. Viçosa, MG, UFV, 1990. 97p. Dissertação (Mestrado em Zootecnia) - Universidade Federal de Viçosa, 1990.

THORLACIUS, S.O., ROBERTSON, J.A. 1984. Effectiveness of anhydrous ammonia as a preservative for high-moisture hay. Can. J. Anim. Sci., 64(4):867-80.

TILLEY, J.M.A., TERRY, R.A. 1963. Two technique for the in vitro digestion of forage crops. J. Br Grassl. Soc., 18:104-111.

VAN SOEST, P.J., FERREIRA, A.M., HARTLEY, R.D. 1984. Chemical properties of fiber in relation to nutritive quality of ammonia-treated forages. Anim. Feed Sci. Technol., $10(2 / 3): 155-164$.

VILELA, D., WILKINSON, J.M. 1987. Efeito do emurchecimento e da adição da uréia sobre a fermentação e digestibilidade in vitro do capim-elefante (Penisetum purpureum, Schum) ensilado. R. Soc. Bras. Zootec., 16:550-562.

WAISS JR., A.C., GUGGOLZ, KOHLER, G.O. et al. 1972. Improving digestibility of straws for ruminant feed by aqueous ammonia. J. Anim. Sci., 35(1):109-112.

YU, Y, THOMAS, J.W. 1976. Estimation of the extent of heat damage in alfalfa haylage by laboratory measurement. $J$. Anim. Sci., 42:766-74.

Recebido em: 14/04/98

Aceito em: 07/07/99 